\title{
Posibilidades educativas de las TIC para población infantil autista: buscadores y software especializado
}

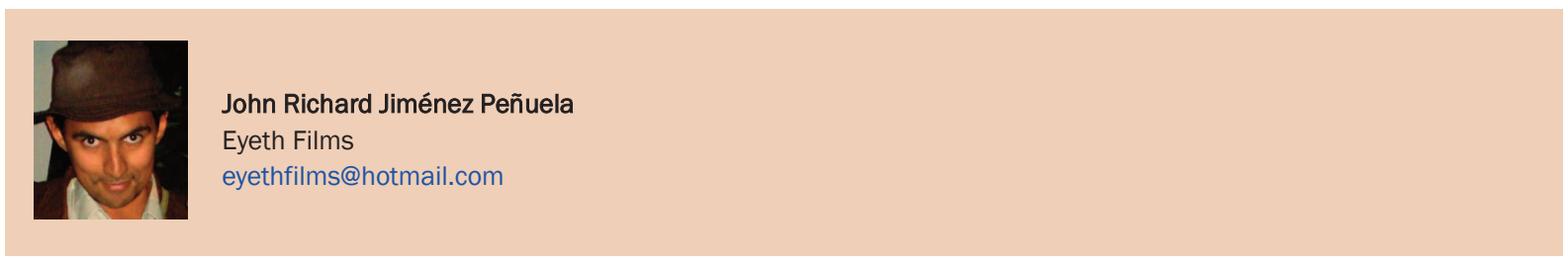

|Fecha presentación: 10/08/2010 | Aceptación: 30/11/2010 | Publicación: 17/12/2010

1. Breve reflexión acerca del autismo y la educación $\mathrm{Al}$ igual que con otras condiciones de discapacidad, con el autismo existe una delgada línea que separa la igualdad de la diferencia, la normalidad de lo que no lo es. Así, se podría afirmar que los individuos en condición de discapacidad poseen todas las particularidades y potencialidades de un ser humano normal. En este afán de querer pertenecer a la normalidad se puede obviar lo particular de su condición, por lo que desde la sociedad y la responsabilidad del Estado se dará por hecho que, como el individuo es igual a los otros, no requiere de educación y adecuaciones de diversos tipos para desarrollarse en la sociedad.

Pero ante los ojos de la sociedad, puede ocurrir lo contrario cuando se observan demasiadas particularidades de las personas en condición de discapacidad, lo cual puede llevar a pensar que son incapaces debido a sus falencias. Por lo tanto, se debe procurar un equilibrio entre ambas posiciones, donde se reconozcan estas particularidades y a su vez las capacidades y posibles talentos, o potencialidades, los cuales pueden desarrollarse por el individuo desde que tenga las condiciones del entorno accesible, de la aceptación social sin discriminación o sobreprotección, del acceso económico a los servicios accesibles y el desarrollo educativo desde la más temprana infancia, en lo posible, respetando las condiciones particulares del individuo, pero involucrado en el ambiente mayoritario educativo.

Es inaceptable que las TIC sean ajenas a estos procesos de reconocimiento en la sociedad de las personas en condición de discapacidad. Es así que hoy por hoy las TIC son una de las columnas que le dan sustento a la sociedad actual, por lo que se hace necesario proporcionar al ciudadano una educación acorde a esta realidad. Las TIC deben ser usadas en el aprendizaje y la enseñanza, facilitando los procesos educativos, pero principal- mente, transformándolos, y permitiendo el acceso del amplio espectro de las sociedades locales a una educación de calidad.

\section{TIC, educación y autismo}

Las TIC no tienen por qué ser un elemento que aísle a las comunidades; por el contrario, se han constituido en un elemento importante en la globalización de la comunicación. Y aunque podría creerse que las TIC hacen a los autistas más autistas, no debe ser así, sino que por el contrario pueden ser un factor positivo para combatir el aislamiento, potenciando las habilidades de interacción social, no solo a través de las redes sociales (que por cierto han sido una forma en que los parientes e interesados con autismo se comunican y dan a conocer sus historias), sino también en el compartir actividades de tipo educativo, de comunicación, de diversión, al trabajar en equipo, al compartir con sus pares, adultos y cuidadores. Dentro de este contexto, se fortalecen habilidades sociales y comunicativas, que a su vez posibilitan las relaciones interpersonales y el reconocimiento de emociones.

Asimismo, el uso de las TIC en el aula de clase debe superar la ejecución de ejercicios y tareas clásicas escolares de mesa y copiar del tablero, por exactamente las mismas pero en un ordenador con el uso de Internet. Más allá del computador como pizarra, las actividades que se desarrollen deben tener una preparación desde la concepción de las diferentes herramientas de software e Internet que posibilitan el desarrollo de las funciones cognitivas y un aprendizaje activo, donde destacan su versatilidad, flexibilidad y adaptabilidad a las condiciones del estudiante. Y por supuesto, esta preparación de la clase de nada serviría si el docente no conoce las condiciones específicas de su estudiante. 
De igual forma, se encuentra que las herramientas web y diferentes programas pueden ofrecer entornos y situaciones repetibles y controlables, por lo que el estudiante podría seguir la misma ruta para encontrar la actividad de su agrado, fortaleciendo la motivación y la atención, su estructuración espacial y temporal, el conocimiento y la comprensión de su entorno, y las habilidades en la lectura de textos no solo escritos, sino visuales, sonoros, multimedia y de otro tipo.

Es así que la estimulación multisensorial de estas herramientas posibilita el trabajo autónomo, así como el desarrollo de las capacidades de autocontrol, desde que las tales tengan objetivos pedagógicos claros acordes a la condición autista.

\section{Accesibilidad web y autismo}

Sin embargo, se encuentra que para el educando autista, características de las páginas web como los colores de los fondos, el diseño y disposición de los banners, y la cantidad, calidad y forma de presentar los contenidos podrían resultar estridentes y constituirse en factores desmotivantes para su acceso a la tecnología.

Por tanto, al diseñar sitios web es necesario cuidar estos aspectos desde un diseño universal no solamente apropiado para la condición autista, sino para otros públicos como lo puede ser el infantil, y las personas con dificultades para la lectura. Es así que, deben preferirse estímulos con opciones claras, con opciones de ayuda y contenidos en diferentes soportes (vídeo, iconos, escritos, audios, videos en lengua de señas, etc.), conllevando diferentes niveles de dificultad, y refuerzos adecuados para las rutas apropiadas a la hora de navegar, evitando los estímulos parasitarios (Tortosa 2002). Es por eso que la búsqueda de contenidos debe ser simplificada, obviando elementos que puedan afectar la concentración, más aún, cuando la comunicación se da de forma no verbal.

Un ejemplo apropiado se encuentra en el ZAC Browser, el primer navegador desarrollado específicamente para niños con autismo, y desórdenes de espectro autista como el síndrome de Asperger, y desorden de desarrollo dominante ${ }^{1}$. Con este navegador se bloquean algunas teclas y funciones a la hora de acceder a Internet, con el fin de evitar que el niño autista se distraiga con funciones secundarias.

Este programa presenta un filtro que bloquea contenidos violentos, sexuales o para adultos, siendo una opción igual de aplicable con otras poblaciones infantiles. Dado que utiliza comunicación no verbal, se constituye también en una excelente herramienta para aquellos que no han aprendido a leer aún, al no existir opciones de texto como requisito para la navegación.

De igual forma, los ambientes de cada una de sus opciones guardan similitud entre sí, y los íconos siempre están en el mismo orden de navegación. La interfaz de usuario es pensada como un acuario, donde el cursor es un submarino que navega por las opciones que se agrandan, en el borde inferior de la pantalla (Figura 1).

Presenta siete menús diferentes. El primero, "Latest website", da acceso a novedades de actividades en Internet. El segundo, "Aquarium", permite regresar a la interfaz inicial. El tercero, “Televisión”, presenta en forma de una pantalla diferentes videos dirigidos a la población infantil, provenientes de sitios web comerciales tales como http://www.disneylatino.com/playhousedisney/ (Figura 2).

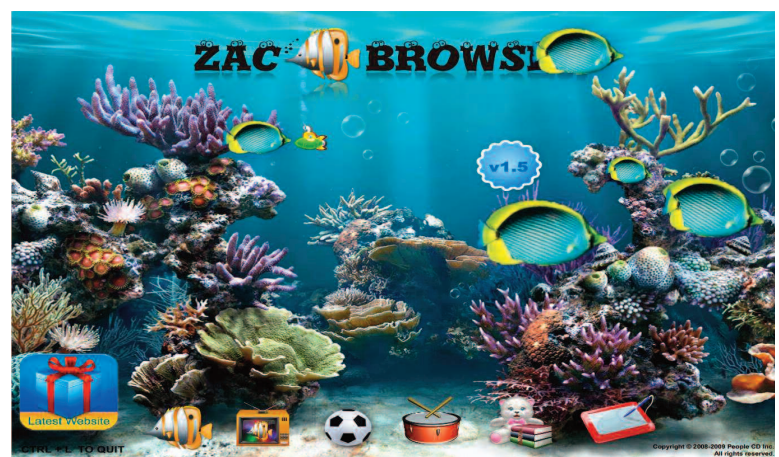

Figura 1.

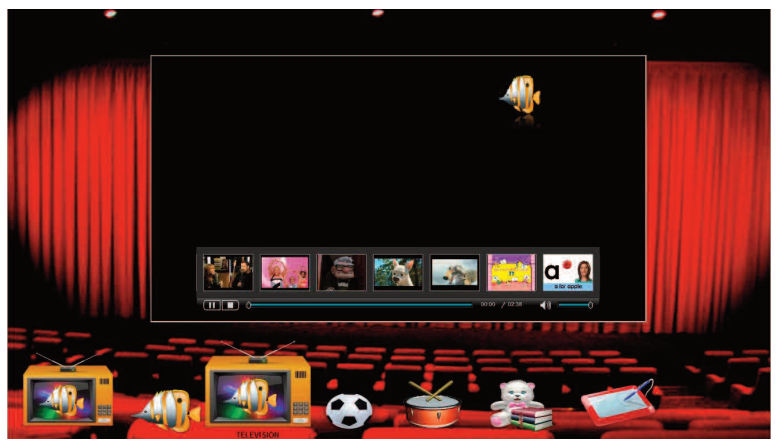

Figura 2.

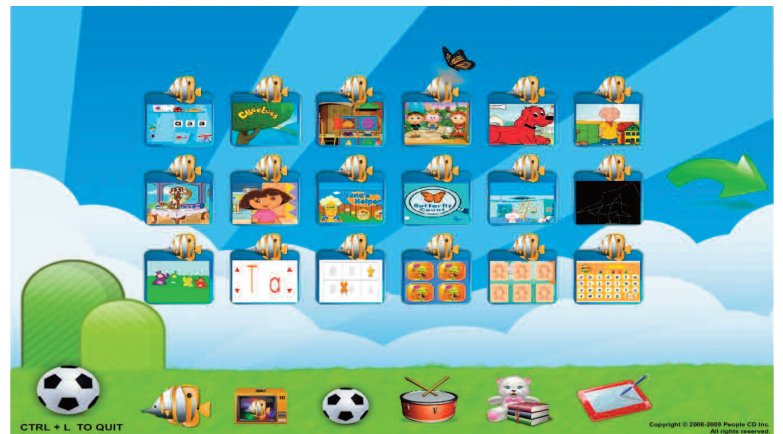

Figura 3.

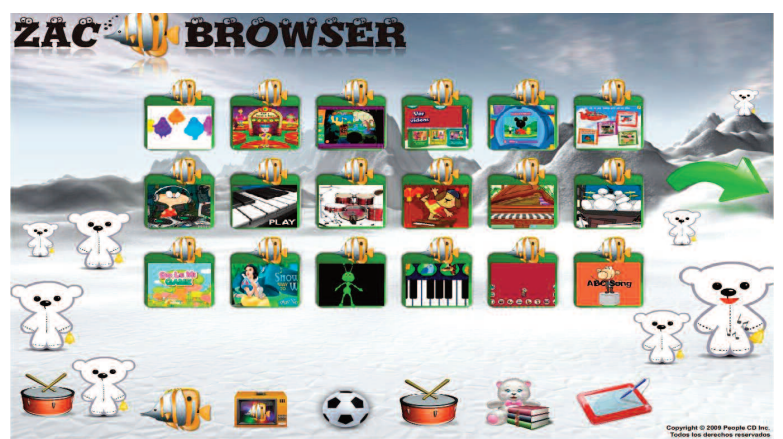

Figura 4. 


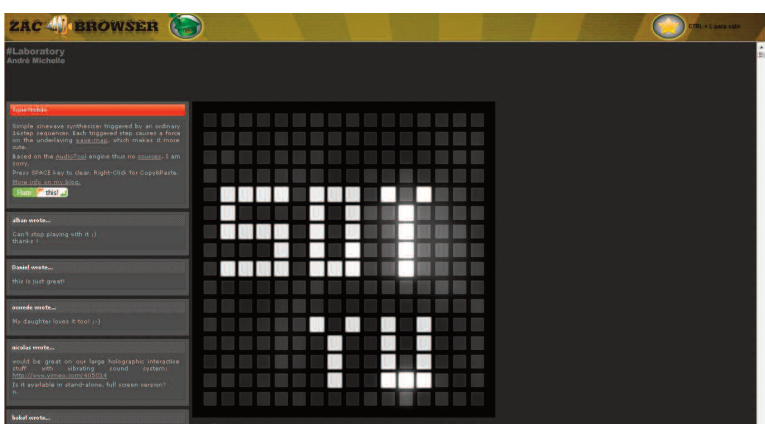

Figura 5.

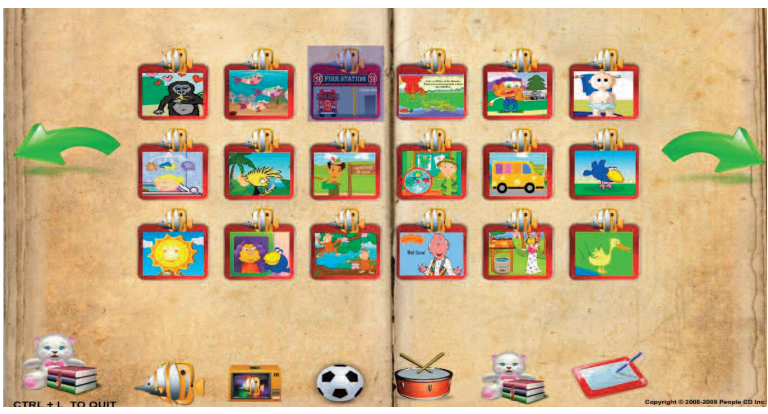

Figura 6.

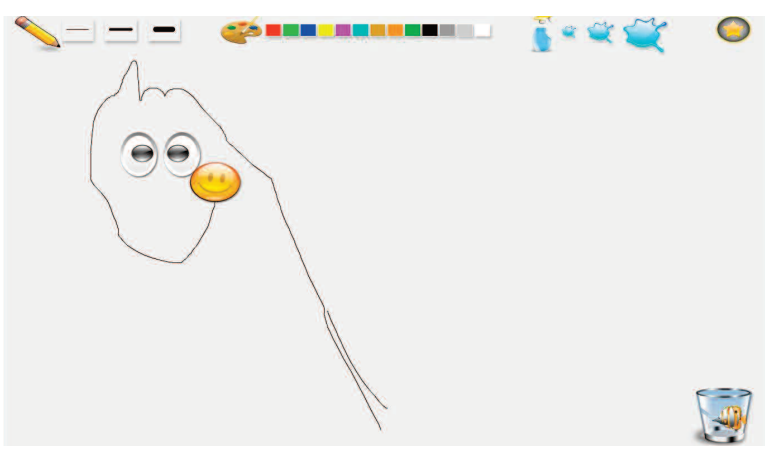

Figura 7.

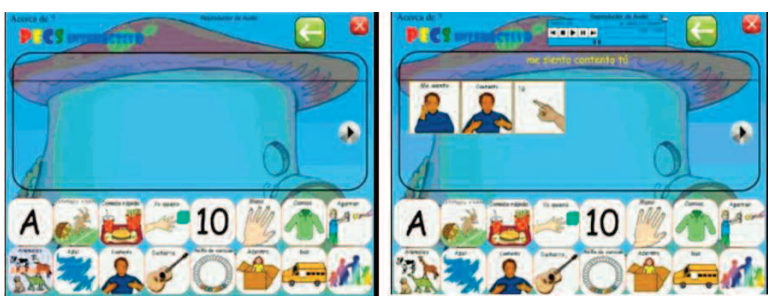

Figura 8.

El cuarto menú "Juegos" (Figura 3), y el quinto "Música" (Figura 4). Respecto a este último, resalta en esta opción las diferentes aplicaciones en línea, que permiten crear melodías al azar, de forma sencilla, como en el caso de la aplicación Tone Matrix (Figura 5), en la que el usuario selecciona los cuadros que guardan una melodía y conforme habilita más cuadros, va creando una melodía más compleja.
Un sexto menú es "Historias" (Figura 6), donde se encuentran cuentos y diferentes animaciones que relatan cortas historias. La interface de esta opción y de "Juegos" son similares. La séptima y última opción es "Pizarra" (Figura 7), similar en su diseño a programas de dibujo como Paint, con una opción quizás pensada en el reconocimiento de rostros, como lo son un par de ojos.

Hay que recordar que el programa solo permite utilizar las opciones habilitadas; es decir, en una página se pueden presentar muchos links, pero el ZAC solo permitirá trabajar en el link preestablecido. Además, la pagina web del programa http://www.zacbrowser.com/es/invitation.html, ofrece un foro a padres y cuidadores donde pueden aprender de otras experiencias, compartiendo historias, donde pueden conectarse y comunicarse con otros que entienden íntimamente sus situaciones.

La página también ofrece las versiones del programa en inglés, español y francés, para ser descargadas como un instalador o como un aplicativo. Una gran ventaja por encima de otros programas diseñados para población autista es su disponibilidad de forma gratuita, garantizando su acceso a un mayor público.

\section{Otros programas accesibles}

En este espacio se mencionarán otros programas diseñados específicamente para población autista.

Gaining Face. Es un software de reconocimiento facial de uso fácil, que permite a los niños aprender a reconocer las expresiones faciales, siendo étnicamente amistoso. Creado por un equipo interdisciplinario de sicólogos, especialistas educativos, programadores y padres de niños autistas es aplicable a varias condiciones de autismo.

Pecs Interactivo. Este un sistema alternativo de comunicación que, como otros sistemas alternativos, se basa en las características del posible usuario, fotografías o imágenes de contexto, categorías básicas como alimentación y vestuario, y la intencionalidad en el material. En este sistema, un símbolo es intercambiado para elegir o pedir algo, o responder lo que se pregunta.

El programa fue diseñado para formar oraciones por medio de imágenes (Figura 8). Permite que personas con problemas de comunicación social formen oraciones animadas de hasta doce imágenes y luego las reproduzcan dando clic en Play. El usuario puede ingresar hasta treinta imágenes aparte de aquellas con las que ya cuenta el programa.

Una de sus ventajas es que permite ser instalado en agendas digitales permitiendo un mejor uso y movilidad. Pero principalmente se encuentra que a través de este sistema alternativo de comunicación se propicia el intercambio físico provocado, se incrementa la espontaneidad, se crean enunciados funcionales a partir de la discriminación entre símbolos y vocabulario aprendido.

Impacte 2 IMágenes PAra ComunicarTE. Si bien no es un programa en sí, sino un complemento, este archivo basado en el mismo sistema de comunicación alternativa del Pecs interactivo, brinda una colección de imágenes digitales, sencillas, especialmente desarrolladas para ser utilizadas en la aplicación informática SICLA ${ }^{2}$, a fin de favorecer la comu-

${ }^{2}$ SICLA 2.0 es un conjunto de aplicaciones informáticas destinadas a servir de soporte a los sistemas aumentativos de comunicación (fundamentalmente los pictográficos). Las principales funcionalidades son: edición de pictogramas, gestión de bibliotecas y usuarios, elaboración de tableros virtuales, comunicación local (síntesis de voz) y comunicación a distancia (correo electrónico y llamadas telefónicas). Mayor información al respecto en: http://www.esaac.org/index.php?option=com_remository\&ltemid=49\&func=select\&id=3. 
nicación a aquellas personas que carecen de habla o el mismo es ininteligible. Sin embargo, estas imágenes pueden utilizarse con cualquier otra aplicación que admita el formato JPG.

\section{Bibliografía}

Tortosa, Francisco (2002). Avanzando en el uso de las TIC con personas con Trastorno del Espectro Autista: usos $y$ aplicaciones educativas. Ponencia presentada al II Congreso Nacional Nuevas Tecnologías y Necesidades Educativas Especiales - TECNONEET 2002. http://www.tecnoneet.org/docs/2002/5-92002.pdf. Consultado el: 29/11/2010.

ZAC Browser: http://www.zacbrowser.com/es/story.html. Consultado el: 29/11/2010. 